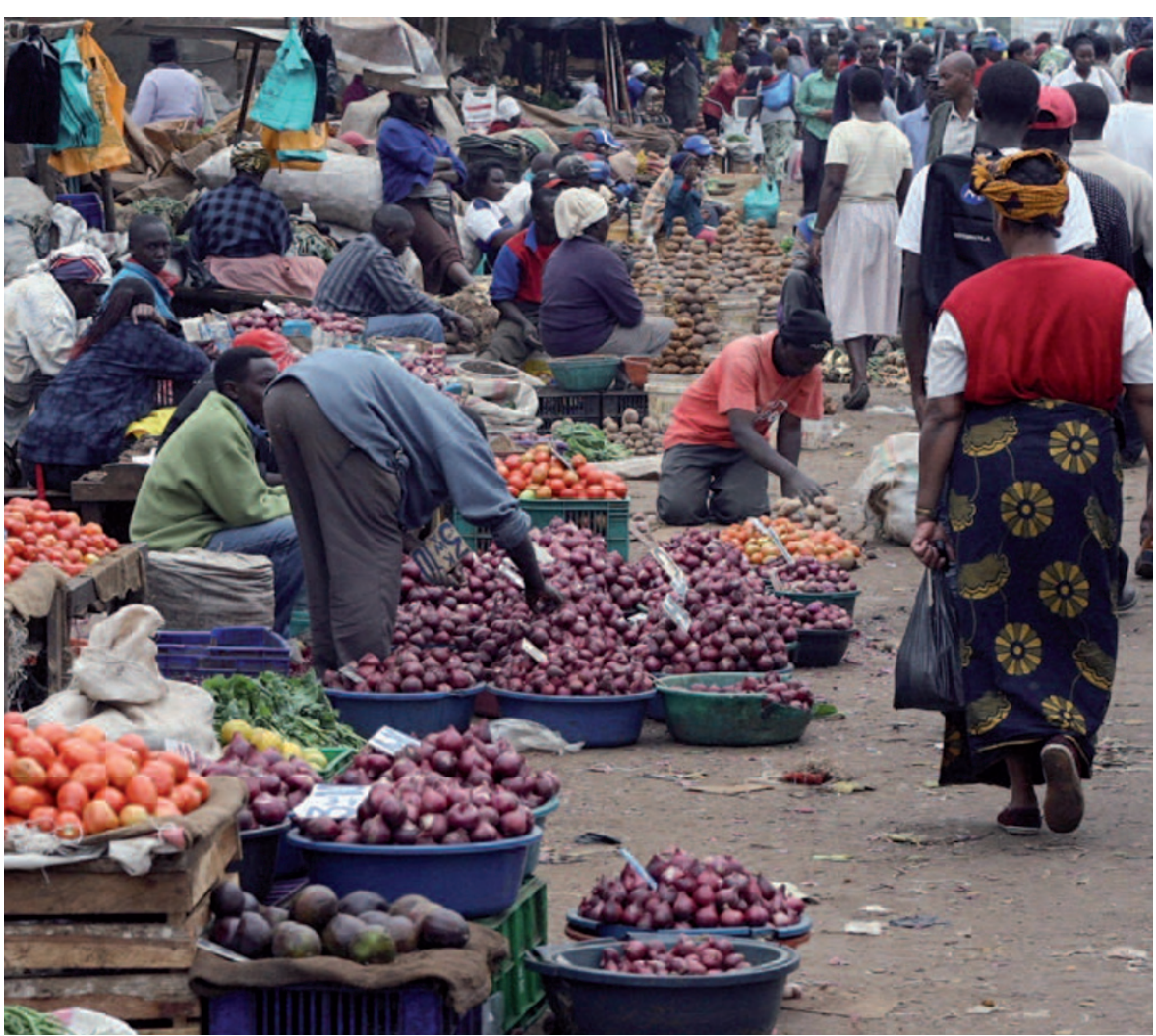

Despite the bounty in this Kenyan market, Africa suffers from poor infrastructure and low productivity.

PERSPECTIVE

\section{A new hope for Africa}

\section{Bioenergy could help bring food security to the world's poorest continent, say Lee R. Lynd and Jeremy Woods.}

$\mathrm{I}$ thas widely been assumed that increased production of energy from biomass requires a sacrifice in food security, particularly for the world's poor. Yet closer scrutiny suggests that modern bioenergy - in the form of fuel, electricity or heat - could be developed in ways that actually enhance food security.

In Africa, where the incidence of food insecurity is highest, hunger persists because of multiple compounding factors: poverty, poorly developed agricultural infrastructure and support, degraded land and armed conflict. Underlying these factors is a legacy of three decades of neglect for agricultural development in the poorest countries of the world.

After the success of the Green Revolution in conquering famine in India, Pakistan and elsewhere in Asia in the 1960s, the world entered a prolonged period of plentiful and cheap food. As documented by Roger Thurow and Scott Kilman in their book Enough: Why the World's Poorest Starve in an Age of Plenty, this abundance shifted attention away from further agricultural development, particularly for Africa. The prevailing thinking in the West was: our food is cheap and abundant; developing countries can buy food from us; if people are hungry, we'll feed them.

Global support for agricultural development in Africahas declined from US $\$ 8$ billion a year in the 1980 s to less than US\$3 billion, and aid from the United States has plummeted more steeply. This period also saw the introduction of the 'structural adjustment' philosophy of fiscal austerity at leading development agencies such as the World Bank. Poor countries were urged to shrink the size of government, disband inefficient public sector enterprises and let the private sector take over. But the private sector was inexperienced and undercapitalized, and both suppliers and lenders considered smallholder farmers to be too poor to be a worthy market.

The result, observes Thurow, was that agricultural schools and research institutes in Africa were woefully underfunded.
Extension services, which had distributed the latest technology and advice to farmers, $\sum_{\Sigma}^{\frac{\pi}{2}}$ were neglected. Rural infrastructure collapsed. Development of storage facilities, farm-to-market roads, rural finance and commodity markets was ignored. Onethird to one-half of agriculture production routinely went to waste before it could get to $\sum_{\bar{c}}^{0}$ a market. African agricultural productivity fell further behind the rest of the world (see

'The Africa lag').

Without government support or financial mechanisms such as futures pricing and crop insurance, Africa's farmers were left bearing all the risk of an inherently risky business. Add to this inferior infrastructure, outdated knowledge and technology, and unimproved seeds, and it is clear why many found it impossible to compete and so abandoned production of surplus crops.

There are some encouraging recent signs. Prompted in part by the food price spike of 2007-2008, the world has refocused attention on global food security. Sensibly, agricultural development is replacing emergency aid as the lead strategy in fighting hunger. In addition, Africa's farmers are now being seen as indispensable if the world is to meet the challenge of roughly doubling its food production to meet predicted increases in population by 2050 . Nowhere else is the potential to increase agricultural yields so great.

Consideration of the impact of bio energy on African food security has tended to focus on land competition and to overlook bioenergy's marked potential to promote rural development. However, potentially productive land is rather plentiful in much of Africa whereas lack of development is the most important underlying cause of hunger. August Temu of the World Agroforestry Centre observes: "Africa has 12 times the land area of India, similar land quality, and $30 \%$ fewer people. And yet India produces enough food to feed itself and Africa does not. The green revolution bypassed Africa primarily owing to serious organizational and institutional weaknesses, not geographically limited capacity."

The impact of bioenergy on food insecurity - and its frequent companions poverty, and underdeveloped rural areas - depends on the crop grown, the land used, the technology employed, and how the bioenergy supply chain is integrated into agricultural, social and economic systems. A range of options need to be considered.

Bioenergy could in principle be produced from inedible plants that grow on land that is not well suited for growing food. Grass has notable potential for regeneration of degraded soils, and plants such as Agave can grow on particularly dry land. Sugar cane requires higher quality land than grass or Agave, whereas annual row crops require the highest quality land. 
Technology is established for electricity production from biomass, and for biofuel production from sugar cane, corn and oil seeds (e.g. soy, sunflower, oil palm, jatropha). This is not, however, the case for biofuel production from grass or Agave fibre. Although oil seeds are more expensive to produce and most yield less fuel per unit land than other crops, they require the least elaborate processing technology and are thus more practical to produce on a small scale. Configurations involving integrated production of food, animal feed and bioenergy are potentially attractive.

Some bioenergy supply chains would make food security worse, whereas others could make it better. Consider the multiple foodsecurity benefits of producing bioenergy from inedible crops grown on marginal land:

-Employment, and development of marketable skills, for rural Africans who have few opportunities for either.

-Introduction of sorely needed agricultural infrastructure and knowhow.

-Improved balance of payments and currency valuation. As economic development proceeds in Africa, demand for electricity and fuel will continue to increase sharply; the cost of importing oil imposes an evergrowing burden on Africa's economies and farmers.

-Energy democratization, selfsufficiency and availability for agricultural processing. Restricted access to clean, affordable energy impedes development and food production, amplifies losses in the food supply chain and exacerbates hunger.

- An economically rewarding way to regenerate Africa's vast areas of degraded land.

-A route to advancing agriculture in Africa, largely independent of factors that have made this difficult in the case of food production. North America and Europe export large amounts of food at prices difficult for African farmers to compete with. But these regions do not export biofuels and are unlikely to do so in the future, and exporting heat and electricity is not feasible.

-Lessened conflict, which is widely recognized as both a cause and an effect of hunger and poverty in Africa. Using bioenergy to improved both food security and economic security could help replace a vicious cycle with a virtuous one.

Crops grown on higher quality land would in general realize the benefits listed above, but the situation is more complex than for marginal land because of stronger interactions with food production. These interactions are a potential asset if managed well, but represent a risk to food security if managed poorly.

Assessments of biomass production potential consistently identify Africa and Brazil as the two regions with the greatest capacity. Although each situation is unique, Africa might hope to replicate Brazil's recent success in several respects.

The past decade has seen $10 \%$ of the Brazilian population lifted out of poverty. Ethanol production nearly doubled during this period, as Brazil has emerged as an international food production and export powerhouse. About half of Brazil's primary energy supply is renewable, and sugar cane provides a third of this from $0.6 \%$ of the country's total land area in a region far from the environmentally sensitive Amazon rainforest. Residues from cane ethanol production have become an important source of electricity, and expanding their use for marginalizes many more.

The question, then, is: what needs to be done to ensure that we cut with the beneficial edge of bioenergy's double-edged sword?

To start with, we suggest that proposed bioenergy projects in Africa be expected to demonstrably improve food security at a local level. This would move the discussion from the abstract to the concrete while honouring legitimate concern over the possibility of exploitation. To achieve this goal will require planning and monitoring. Emerging frameworks and standards for evaluating bioenergy, such as those of the Roundtable on Sustainable Biofuels and the Global Bioenergy Partnership, will need to be adapted to the African context. Privatepublic partnerships are in principle attractive ways to harness the economic engine of private enterprise in order to realize social benefits. Farmer cooperatives could be a way to aggregate the output and represent the interests of smallholder farmers supplying biomass processing facilities. Research is needed on biomass production, conversion technologies and societal integration, emphasizing Africa-specific aspects.

Important strategic issues include the different attributes of village-scale and industrial-scale processing, the need to implement near-term options in ways that foster rather than impede deployment of advanced technologies as they become available, and how to access export markets in ways that serve the needs and aspirations of Africans.

As humanity faces the multiple challenges of our time, our need to avoid the many approaches that do not foster sustainable outcomes is
196519701975198019851990199520002005 cattle feed is under consideration. Brazil has analysed the impacts of its ethanol industry, documenting macroeconomic benefits as well as increases in the income of labourers and in the level of education and nutrition available to their children.

Like Brazil, Africa has the geographical capacity to produce much more food and bioenergy than it requires, while using water sustainably and not compromising biodiversity. We believe that bioenergy can, increasingly over time, improve the food security and well-being of poor Africans, thus turning an assumed liability into an asset.

Three outcomes are possible. First, Africa's bioenergy potential could go undeveloped. Given the continent's pressing and persistent problems, this would be unfortunate. Second, bioenergy could be developed in ways that increase food security and prosperity for poor Africans. And third - the big concern - bioenergy could be developed in a way that benefits few people and further exceeded only by our need to identify and implement the (probably fewer) approaches that do. Bioenergy is a case in point. The first step towards reaching 'win-win' outcomes with respect to bioenergy, food security and poverty reduction is to recognize that such outcomes are possible.

Lee R. Lynd is a professor at Dartmouth College's Thayer School of Engineering in Hanover, New Hampshire, and coordinator of the executive committee of the Global Sustainable Bioenergy project. Jeremy Woods is a lecturer at Imperial College London, and codirector of the Porter Alliance.

e-mails:lee.r.lynd@Dartmouth.edu; jeremy. woods@imperial.ac.uk

We thank R. Thurow for discussions about the causes of food insecurity in Africa, and C.H. Brito Cruz of the Sao Paulo Research Foundation for information about bioenergy in Brazil. 